\title{
Mobile app as a fetal monitoring aid - a pilot study
}

\section{Karoline Berg}

Jordmor

Avdeling for gynekologi og fødselshjelp, Bærum sykehus

\section{Eirin Haave}

Jordmor

Fødeavdelingen, Oslo universitetssykehus, Ullevål

\section{Ellen Blix}

Professor I

Fakultet for helsevitenskap, Oslomet - storbyuniversitetet

\section{Aase Devold Pay}

Assisterende avdelingsleder og førsteamanuensis

Fødeavdelingen, Oslo universitetssykehus og Fakultet for helsevitenskap, Oslomet storbyuniversitetet

Childbirth

$$
\text { Observation Group interview }
$$

\section{Summary}

Background: Using a fetal stethoscope to listen to the fetal heart rate requires both knowledge and experience. Concern has been expressed among healthcare personnel that newly qualified midwives do not learn how to use a fetal stethoscope, and that in the future midwives will rely more on advanced technology than on simpler tools and their own skills. The authors behind this study have been involved in the development of a new mobile app that can serve as an aid when using a fetal stethoscope. 
Purpose: The purpose of the study was to investigate midwives' experiences with fetal stethoscopes, including their experiences of using PocketPinard as an aid, and whether the app can be useful in practice.

Method: We conducted a qualitative pilot study in the spring of 2019. Five midwives were given 30 minutes to try out the app. Data were obtained from focus group interviews and analysed using Malterud's four-step text condensation method.

Results: Four of the informants were not confident in using the fetal stethoscope and experienced practical challenges. It was found that using PocketPinard together with a fetal stethoscope could make them feel more confident. The informants believed that the app would be particularly useful for skills enhancement and training purposes. The pilot study revealed challenges with the graphical representation of heart rate over time. The graphical representation is open to error because the user has to press a button to record the fetal heart rate. This will be investigated in any further development of the app.

Conclusion: Several of the informants lacked confidence in using a fetal stethoscope and felt unsure about how to use it. The PocketPinard made them feel more reassured because the heart rate was displayed in a graphical representation. The app appears to be a potentially useful aid for training and practice in using the fetal stethoscope. The findings of this pilot study are useful for the further development and testing of the PocketPinard app.

Fetal monitoring involves observation of the fetal heart rate. During pregnancy and childbirth, changes in the fetal heartbeat may be an indication of a lack of oxygen (1). Where oxygen deficiency is indicated, early identification and delivery can help prevent serious injury and death (2). In prenatal care, the fetal heart rate is examined regularly from week $24-26$ using a fetal stethoscope or handheld Doppler device (3). 
There are two principles of fetal monitoring during labour: intermittent auscultation (IA) and continuous fetal monitoring $(1,4)$. A fetal stethoscope or handheld Doppler device is used for IA. The midwife checks the fetal heart rate every 15 to 30 minutes and palpates contractions manually. Cardiotocography (CTG), which continuously records the fetal heart rate and the frequency of contractions, is used for continuous fetal monitoring. Norwegian and international guidelines recommend IA with a fetal stethoscope or handheld Doppler device for low-risk deliveries and continuous monitoring with CTG for high-risk deliveries $(1,4)$.

Continuous fetal monitoring is also widely used for low-risk mothers, despite the recommendations $(5,6)$. Routine use of CTG can lead to more interventions being carried during labour without these necessarily improving the outcome (7).

\section{Using a fetal stethoscope and Doppler}

Until a couple of decades ago, the fetal stethoscope was in widespread use in Norway. The stethoscope is usually wooden, $15-50 \mathrm{~cm}$ long and takes the form of a stem with a funnel at the end. The user places the funnel on the patient's abdomen and listens through the stem. The user hears the sounds of the heart valves closing. The benefit of using a fetal stethoscope is that it is inexpensive and rarely breaks (8).

A handheld Doppler is a small ultrasound device that uses the Doppler effect to create an audible simulation of the fetal heart rate. The advantages of the Doppler device are that it can be used no matter what position the woman is in and that everyone in the room can hear the heart sounds. The device is more expensive than a fetal stethoscope, breaks more easily and is dependent on batteries. 
Four randomised studies have examined the effect of the Doppler device compared to the fetal stethoscope, and the results of these studies have been conflated in a meta-analysis (9). The four studies included a total of 8436 women and were held in Zimbabwe, Uganda and Tanzania.

Abnormal fetal heart sounds were found more often in women who were randomised for examination with a Doppler device than in those examined with a fetal stethoscope. However, there was no difference in outcome, and the authors concluded that there is no evidence base for recommending a Doppler device instead of a fetal stethoscope or vice versa.

The Norwegian Directorate of Health's guide on quality in maternity units sets requirements for skills in fetal monitoring at maternity units, including the requirement for obstetricians and midwives to be capable of using a fetal stethoscope (10).

Since 2017, the Medical Birth Registry of Norway has registered what equipment is used to monitor fetal heart rates. Only 5 per cent of maternity patients were monitored using a fetal stethoscope, and the proportion varied from $\circ$ to 28 per cent at the various health trusts (11).

\section{Objective of the study}

There is reason to believe that auscultation with a fetal stethoscope is about to disappear completely in Norway. Using a fetal stethoscope requires both knowledge of and experience in interpreting heart sounds and is a skill that may be lost if it is not maintained as part of regular clinical practice.

We wanted to find a method that could simplify the training in and use of fetal stethoscopes, and to this end created the mobile app PocketPinard (a pinard being another word for a fetal stethoscope). 
The objective of this pilot study was to examine midwives' experiences of using a fetal stethoscope. We also wanted to find out what midwives thought of PocketPinard as an aid in fetal monitoring, and whether the app can be useful in practice.

\section{Method}

\section{Developing PocketPinard}

PocketPinard is a mobile app for recording the observed fetal heart rate and can be used as a training aid for the use of fetal stethoscopes (Figure 1).

The idea for PocketPinard stemmed from the first and second authors, and the app was developed together with experts at the University of Oslo. The design and prototype of the app were completed in May 2019. The app is compatible with both iOS and Android, but is not yet available for download as of May 2021.

Figure 1. Screenshot of PocketPinard

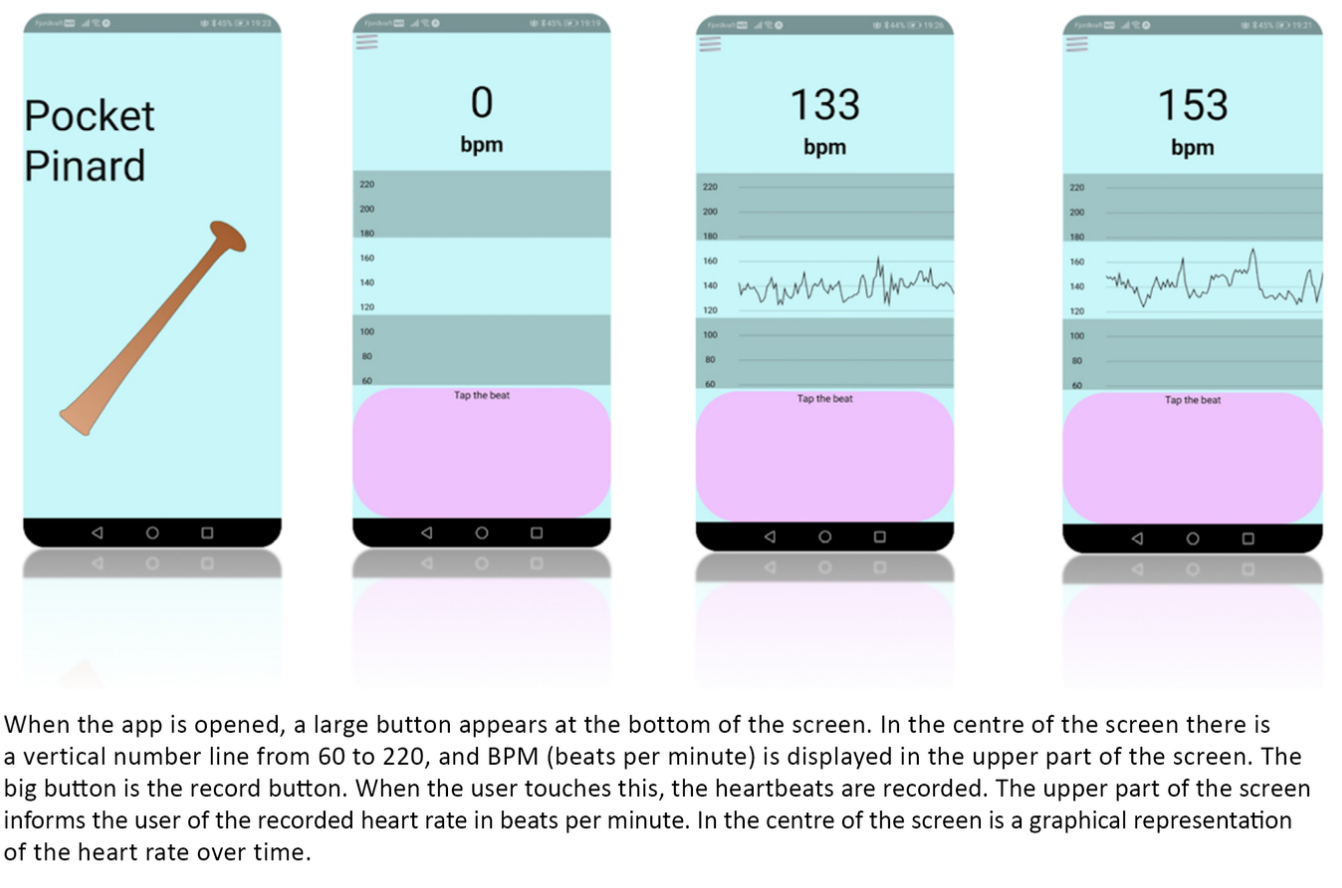

\section{Design}

The pilot study has a qualitative design. Midwives met in a focus group, where they discussed and focused on the use of fetal stethoscopes, PocketPinard and the potential benefits of the app in fetal monitoring. The various functions of PocketPinard were also discussed. 


\section{Sample}

The participants in the study were recruited via social media and using the snowball method. We posted an ad on a nationwide Facebook group for midwives, giving information about participation in the study. The ad received a low response, so we also contacted midwives directly, who passed on the invitation to participate to colleagues. The participants were recruited between 1 April and 31 May 2019.

The sample consisted of five midwives who were employed in different birthing units at maternity clinics under the South-Eastern Norway Regional Health Authority. The median age was 40 and the age range was 31 to 50 years. Two of the respondents had less than five years' midwifery experience. One had five to ten years of experience, while two had more than ten years of experience as a midwife.

\section{Testing}

We invited participants to individual meetings to test out the app. The meetings were held in the period $5^{-11}$ June 2019 and lasted 30 minutes. At the meetings, we gave an introduction to the app and provided information on how to use it. One of the authors was 25 weeks pregnant when the app was tested and was used as a test subject. The informants tested the app within the allotted time. We endeavoured to minimise the exchange of views during the testing.

\section{Data collection}

We conducted focus group interviews using a semistructured interview guide to collect data. Focus group interviews are a suitable method for collecting data for use in development processes (12).

A semi-structured interview guide enabled us to elicit answers to questions on key topics that could shed light on the objective of the pilot study. We developed the interview guide in collaboration with app developers and users (midwives), and tested it on a midwife prior to data collection. 
The data were collected on 11 June 2019. The first author moderated the focus group interviews. The second author participated in the interviews and documented the group dynamics. During the interviews, it was important to ensure that all participants aired their views, and that the dialogue was guided by the topics in the interview guide. The participants' experiences were expressed at group level, but also as individual experiences.

The interview guide contained questions about experience and use of fetal stethoscopes, use of PocketPinard and its various functions, and its potential benefits as an aid when using a fetal stethoscope.

The interviews took the form of a conversation, but the participants were encouraged to ask each other questions and comment on each other's input. The focus group interviews lasted about an hour and were conducted at the midwives' workplaces during working hours.

\section{Analysis}

We made an audio recording of the interviews using the Nettskjema-diktafon app, which ensures secure storage of research data (13). The interviews were subsequently transcribed, and the content formed a 23-page document. We used Malterud's systematic text condensation method in the analysis $(12,14)$.

We formed an overall impression of the material by listening to the interviews several times. We then formulated topics and these provided the basis for further analysis. Meaning units in the text were arranged under the different topics before the text was again divided into smaller groups. Each sub-group formed a natural division in a complex analytical text that was finally illustrated with a golden quote. Golden quotes reflect the content of the text. See Table 1 for an extract of the analysis. 
Table 1. Systematic text condensation - extract from the analysis

\begin{tabular}{|l|l|l|l|l|}
\hline Meaning units & Code & Sub-group & Condensed text & Category \\
\hline $\begin{array}{l}\text { 'I think I would have done } \\
\text { it. Because using it gave } \\
\text { me a taste for it. And will } \\
\text { mean a greater focus } \\
\text { on it.' }\end{array}$ & $\begin{array}{l}\text { Generalisability to } \\
\text { practice and possi- } \\
\text { ble applications for } \\
\text { PocketPinard }\end{array}$ & $\begin{array}{l}\text { Motivation } \\
\text { for use }\end{array}$ & $\begin{array}{l}\text { 'I really want to test it in prac- } \\
\text { tice, because using it gave me } \\
\text { a taste for it. And will mean a } \\
\text { greater focus on it.' }\end{array}$ & $\begin{array}{l}\text { PocketPinard for } \\
\text { training and skills } \\
\text { enhancement } \\
\text { purposes }\end{array}$ \\
\hline $\begin{array}{l}\text { I think if I hadn't had } \\
\text { any aids other than a fetal } \\
\text { stethoscope and a phone } \\
\text { with that app, then it } \\
\text { would have been } \\
\text { helpful.' }\end{array}$ & & $\begin{array}{l}\text { 'The app would have been } \\
\text { helpful if I hadn't had any } \\
\text { monitoring methods available } \\
\text { other than the fetal stetho- } \\
\text { scope, and then I would've } \\
\text { used them together to be } \\
\text { absolutely certain about what I } \\
\text { was hearing.' }\end{array}$ & \\
\hline $\begin{array}{l}\text { I think you can train } \\
\text { yourself so that you don't } \\
\text { need to use the app. But I } \\
\text { think it's great for building } \\
\text { the skills you need.' }\end{array}$ & & $\begin{array}{l}\text { 'Most of those who aren't con- } \\
\text { fident in using a fetal stetho- } \\
\text { scope will feel more confident } \\
\text { with an app like this.' }\end{array}$ & \\
\hline $\begin{array}{l}\text { 'The app can be good } \\
\text { for training and skills en- } \\
\text { hancement, and can give } \\
\text { you more confidence in } \\
\text { listening.' }\end{array}$ & & $\begin{array}{l}\text { Golden quote: I think it would } \\
\text { be good to use the app for } \\
\text { training and skills enhance- } \\
\text { ment purposes as it builds } \\
\text { confidence in listening.' }\end{array}$ \\
\hline
\end{tabular}

\section{Ethical considerations}

The study was approved by the Norwegian Centre for Research Data (NSD) (reference number 659344). All informants received written information about the purpose of the study, a consent form and contact information. The data were treated confidentially, and the transcribed material was permanently deleted after use in accordance with the Personal Data Act (15).

\section{Results}

Following the analysis process, we formulated four categories: 'Uncertainties and practical challenges associated with using a fetal stethoscope', 'Reassurance and better control of the fetal heart sounds', 'Opportunities and challenges of the app's functions' and 'PocketPinard for skills enhancement and training purposes'.

\section{Uncertainties and practical challenges associated with using a fetal stethoscope}


Four out of five informants stated that they rarely or never use a fetal stethoscope in intrapartum patients. Nevertheless, they believed that it was important to use the tool, and expressed a desire to use it more often. Challenges such as fetal position, maternal obesity, a large amount of amniotic fluid or noise in the delivery room were highlighted as barriers to using a fetal stethoscope.

\section{«I don't feel confident using a fetal stethoscope. It's much easier to use a Doppler.»}

Informant

Lack of experience or confidence were nevertheless the crucial factors for several of the informants using other monitoring methods. One informant described it as follows: 'I don't feel confident using a fetal stethoscope. It's much easier to use a Doppler, but I'd like to become more adept at using a fetal stethoscope.'

The informants described how identifying the basal frequency (mean fetal heart rate) was particularly difficult. Most thought they would hear if there were decelerations (a transient decrease in heart rate) or accelerations (a transient increase in heart rate) when using a fetal stethoscope, even if they were unable to determine the exact basal frequency. Several of the participants felt more confident using a Doppler device or CTG on intrapartum patients.

It also emerged that using a Doppler device could give the impression that the midwives appear more professional, and that the sound of the fetal heart can be heard by more people, thus helping to reassure the parents: 'Many of the midwives feel that the parents have more faith in the Doppler - or feel reassured when they hear the heartbeat. It can seem a bit more professional than a wooden trumpet-looking instrument.' 


\section{Reassurance and better control of the fetal heart sounds}

All the informants believed that PocketPinard would provide more reassurance for obstetricians and midwives with little experience of using a fetal stethoscope. One of the informants believed that the app could make it easier to understand the rhythm of the fetal heartbeat, and that it could thus function as an aid to identifying abnormalities.

In addition, another informant thought that PocketPinard was beneficial because it enabled them to listen to the heartbeat whilst also getting a reading of the sounds. She thought this gave them a more detailed overview of the condition of the fetus, and made the following comment: 'It's a combination of technology and the midwife's handiwork.'

Several informants believed that PocketPinard's functions can be equated with the Doppler device, as both give a visual presentation of the fetal heart rate, which means that both tools can identify abnormalities. The informants also discussed in the group interviews whether PocketPinard can help midwives' decision-making.

Some thought that the app helps to identify abnormalities in the fetal heart rate, and therefore provides support for making decisions. Other more experienced informants believed they could hear abnormalities using just the fetal stethoscope, and therefore did not need PocketPinard to make decisions.

\section{Opportunities and challenges of the app's functions}

PocketPinard's design was described as simple, intuitive and very user friendly. The informants provided more input on the app's functions and ideas for further development. One informant pointed out that it can be difficult to handle the fetal stethoscope and mobile phone at the same time. 
Other objections to implementing the app related to hygiene and whether a mobile phone in the delivery room might create distance between the midwife and the patient.

The informants also discussed the app's graphical representation of the heart rate over time. They questioned whether this representation should be part of the app's features.

One midwife thought it would be difficult to classify accelerations, decelerations and variability (fluctuations in heart rate) when heart rate over time is based on how the finger touches the screen, which would mean that some heartbeats could be incorrectly recorded.

She believed that such a function could pose a risk if the graphic representation is misinterpreted, and that the obstetrician or midwife must therefore be aware of the app's limitations when using it. She described it as follows: 'I'm not sure if you can show any real variability. But I'm not sure if that's an argument for not having a graph, you just have to be aware of it. You mustn't be fooled into thinking that there is necessarily good variability when you use the app.'

Suggestions for further development concerned implementing a clock or timer to show how long the user has been listening, and how long any deceleration lasts. Others thought it would be useful to have an auditory presentation of the information recorded by the midwife in the app, so that the parents can hear the heartbeat rhythm.

One respondent suggested adding a log or save function, so that midwives have the opportunity to look back at the recorded heartbeat during labour in order to identify changes along the way. Several informants thought that this would enable PocketPinard to function as a good documentation tool. 


\section{PocketPinard for skills enhancement and training purposes}

All the informants indicated that they would like to use the app, and believed that it could be useful for training purposes due to the graphical representation of the recorded heart rate. Several of the participants thought that PocketPinard could increase the focus on using a fetal stethoscope in the department, and regarded the app as a positive contribution to learning. As one informant said: 'I really want to test it in practice, because using it gave me a taste for it. And will mean a greater focus on it.'

Furthermore, the informants believed that the app could have a huge potential for training and practice in the use of the fetal stethoscope, both in the midwifery study programmes and in the maternity wards. One of the informants said: 'I think it would be good to use the app for training and skills enhancement as it builds confidence in listening.'

\section{«The informants believed that the app could have a huge potential for training and practice in the use of the fetal stethoscope.»}

The informants also discussed other potential applications of PocketPinard, but there was no consensus in the group on whether they would add value to the app or not. Several of the informants also saw opportunities for PocketPinard in low- and middle-income countries, which have little access to electronic monitoring equipment, but where many have a mobile phone and can easily download the app.

One informant with experience from abroad commented as follows: 'I was in clinical practice in Tanzania, and there were very few Dopplers there. It was mostly fetal stethoscopes that were used. But the strange thing is that everyone has a modern phone.' 
Another informant thought that there might not be a need for PocketPinard as a supplementary tool in lowand middle-income countries since the midwives there are already experienced in using fetal stethoscopes.

\section{Discussion}

\section{Using a fetal stethoscope}

Despite the fact that all informants highlighted features of the fetal stethoscope that make it a good tool for fetal monitoring, several members of the group rarely used it in delivery situations. The informants in our study said that lack of experience and confidence were the main reasons why they chose other monitoring tools.

In a meta-analysis from 2012, Smith et al. found that confidence was one of the factors that came into play when midwives had to choose monitoring tools (16). The analysis also revealed that CTG may provide reassurance because it provides objective documentation of the fetal heartbeat, and can therefore be used as evidence in regulatory checks and legal proceedings.

'Defensive medicine' is a well-known term in medical ethics and refers to the practice of undertaking assessments and interventions that are not necessarily the best option for the patient, but mainly serve to cover the backs of the healthcare personnel. The phenomenon is known to create insecurity among healthcare personnel and increase the use of technology and the number of unnecessary interventions (17).

\section{PocketPinard as a fetal monitoring aid}

The results of our study show that PocketPinard can provide reassurance to users of fetal stethoscopes. The informants were satisfied with the app's design and user friendliness, and all wanted to try out the app in the clinical setting. However, they pointed out what they perceived as negative aspects of using the app, including the possibility that PocketPinard might create distance between the midwife and the patient. 
The fear of reducing the contact between the patient and staff is considered to be one of the biggest barriers to successful implementation of technical solutions in the health sector (18). If PocketPinard is perceived as doing just that, the midwives may be less inclined to use the app in practice.

\section{«When testing the app, the informants found weaknesses in the app's graphical representation of heart rate over time.»}

When testing the app, the informants found weaknesses in the app's graphical representation of heart rate over time; if the midwife presses the button on the mobile phone incorrectly when recording the fetal heart rate, this can lead to errors in the presentation of the heart rate over time and ultimately misinterpretations of accelerations, decelerations or variability.

These inputs are important, as misinterpreting the condition of the fetus can lead to incorrect measures or treatment for mother and infant. Initially, we thought it was important to include a graphical representation of the fetal heart rate. However, testing and focus group input have shown that the graphical representation may present problems. This will be investigated if the app is developed further.

\section{Benefits as a tool for training and skills enhancement}

The informants agreed that PocketPinard has great potential as a training and skills enhancement tool for student midwives or for obstetricians and midwives with little experience in using a fetal stethoscope.

In a Norwegian study in which retired midwives were interviewed, the informants worried that newly qualified midwives do not learn how to use the stethoscope and that they will come to rely on technology more than on their own skills (19). 
Experienced midwives internationally also share the concern that the fetal stethoscope will disappear from the clinical setting due to lack of training and experience among those who are newly qualified (20). PocketPinard can make it easier to practise using the fetal stethoscope.

\section{Method discussion}

Our study was a pilot study that included only five midwives. The results cannot be generalised to other midwives or other healthcare personnel. The study's reliability may have been affected by the authors' participation in the development of the app.

Throughout the process, we have been aware of the potential for misinterpretation on account of our vested interest in the app. We therefore adopted a reflective approach, where we recognised both the potential and the challenges of developing the product. We also applied this approach to the focus group interviews, where we wanted honest feedback about the app. The respondents were therefore informed prior to interview that we were open to all conceivable input from them.

\section{Strengths and weaknesses of the study}

The pilot test based on data from the focus group interviews provided important information about the functions of the PocketPinard prototype. The informants' experience and use of fetal stethoscopes varied and led to a range of information being generated about how the app can be used, and about possible benefits in the clinical setting. The informants considered the app to be a relevant aid, and the study has helped to clarify its potential.

\section{Conclusion}


Several of the informants felt uncertain and lacked confidence in using a fetal stethoscope. They thought that the visual representation of the heart rate in PocketPinard could provide reassurance. The app was thought to have the greatest potential as an aid for student midwives and for training staff in how to use a fetal stethoscope. The findings of this pilot study are useful for further development and testing of the PocketPinard app.

\section{References}

1. Yli B KJ, Eikeland T, Henriksen T, Hjelle S, Blix E, Jettestad $\mathrm{M}$, et al. Fosterovervåkning under fødsel, avnavling og syre-baseprøver fra navlesnor. In: Veileder i fødselshjelp. Norsk gynekologisk forening, ed. Oslo: Den norske legeforening; 2020. Available at: https://www.legeforeningen.no/foreningsledd/fagme d/norsk-gynekologisk-forening/veiledere/veileder-ifodselshjelp/fosterovervakning-under-fodselavnavling-og-syre-baseprover-fra-navlesnor-2014/ (downloaded 01.02.2021).

2. Jackson K MJ, Brydon S. Physiology and care during the first stage of labor. In: Marshall J, Raynor M, eds. Myles textbook for midwives. Philadelphia: Churchill Livingstone Elsevier; 2014. pp. 161-71.

3. Helsedirektoratet. Nasjonalfaglig retningslinje for svangerskapsomsorgen. Oslo: Helsedirektoratet; 2018.

4. NICE. Intrapartum care for healthy women and babies. Clinical guideline CG19o. Storbritannia: National Institute for Health and Care Excellence (NICE); 2014.

5. Kaasen A, Aanstad KJ, Pay ASD, Økland I, Blix E. National survey of routines for intrapartum fetal monitoring in Norway. Acta Obstetricia et Gynecologica Scandinavica. 2019;98(3):390-5. 
6. Rosset IK, Lindahl K, Blix E, Kaasen A.

Recommendations for intrapartum fetal monitoring are not followed in low-risk women: a study from two Norwegian birth units. Sexual \& Reproductive Healthcare. 2020;26:100552.

7. Alfirevic Z, Devane D, Gyte GM, Cuthbert A. Continuous cardiotocography (CTG) as a form of electronic fetal monitoring (EFM) for fetal assessment during labour. The Cochrane Database of Systematic Reviews. 2017;2(2):Cdoo6o66.

8. Read B. Fetal heart rate monitoring in labour. In: Chapman V, Charles C, eds. The midwife's labour and birth handbook. 4th ed. Oxford: John Wiley \& Sons; 2017. pp. 61-74.

9. Blix E, Maude R, Hals E, Kisa S, Karlsen E, Nohr EA, et al. Intermittent auscultation fetal monitoring during labour: a systematic scoping review to identify methods, effects, and accuracy. PloS one. 2019;14(7):eo219573.

10. Helsedirektoratet. Et trygt fødetilbud. Kvalitetskrav til fødselsomsorgen. Veileder IS-1877. Oslo: Helsedirektoratet; 2012.

11. Folkehelseinstituttet. Medisinsk fødselsregister. Statistikkbank 2019. Available at: http://statistikkbank.fhi.no/mfr/ (downloaded 01.03.2020).

12. Malterud K. Fokusgrupper som forskningsmetode for medisin og helsefag. 3 rd ed. Oslo: Universitetsforlaget; 2012.

13. Universitetet i Oslo (UiO). Nettskjema-diktafonappen. Oslo: $\mathrm{UiO} ; 2019$ [updated 15.05.2019, cited 15.05.2019]. Available at: https://www.uio.no/tjenester/it/admapp/nettskjema/hjelp/tips-triks/diktafon.html 
14. Malterud K. Kvalitative forskningsmetoder for medisin og helsefag. 4th ed. Oslo: Universitetsforlaget; 2017 .

15. Lov 15. juni $2018 \mathrm{nr} .38 \mathrm{om}$ behandling av personopplysninger (personopplysningsloven). Available at: https://lovdata.no/dokument/NL/lov/2018o6-15-38 (downloaded 01.08.2019).

16. Smith V, Begley CM, Clarke M, Devane D. Professionals' views of fetal monitoring during labour: a systematic review and thematic analysis. BMC Pregnancy and Childbirth. 2012;12:166.

17. Ruyter KW, Førde R, Solbakk JH. Medisinsk og helsefaglig etikk. 3rd ed. Oslo: Gyldendal Akademisk; 2014 .

18. Gagnon MP, Ngangue P, Payne-Gagnon J, Desmartis M. M-health adoption by healthcare professionals: a systematic review. Journal of the American Medical Informatics Association: JAMIA. 2016;23(1):212-20.

19. Walthinsen MB CE. Erfaringer med jordmorstetoskopet før utstrakt bruk av elektronisk fosterovervåkning. Intervjuer med pensjonerte jordmødre i Norge [masteroppgave]. Oslo: Oslomet storbyuniversitetet; 2018.

20. Smith H. Maintaining the passion for pinards. The Practising Midwife. 2013;16(8):26, 28-9.

21. McCurdie T, Taneva S, Casselman M, Yeung M, McDaniel C, Ho W, et al. Mhealth consumer apps: the case for user-centered design. Biomedical Instrumentation \& Technology. 2012;Suppl:49-56. 